\title{
Uma análise sobre a logística e suas interconexões com o território: os casos do Centro Logístico Industrial Aduaneiro de Ponta Grossa e do Aeroporto de Cargas dos Campos Gerais do Paraná
}

\section{An analysis on logistics and its interconnections with the territory: case studies of the Industrial Logistic Customs Center and the Cargo Airport of the Campos Gerais region, state of Paraná}

Sueli Aparecida Nascimento

Edu Silvestre de Albuquerque

Universidade Estadual de Ponta Grossa

\begin{abstract}
Resumo: Entre o final dos anos 1980 e durante os anos 1990 acontece uma intensa abertura da economia brasileira ao comércio internacional, (re)surgindo assim a questão da organização do território fundamentada na procura da otimização e da fluidez, de forma a intensificar a circulação de mercadorias e de informações, a especialização da produção e a intensificação da divisão do trabalho. A logística territorial volta a frequentar a agenda política nacional e regional como forma de trazer maior competitividade às empresas, como no caso dos projetos do CLIA - Centro Logístico Industrial Aduaneiro de Ponta Grossa - e do Aeroporto de Cargas de Tibagi, na região dos Campos Gerais do Paraná. Neste artigo são demonstrados os limites destes projetos segundo os conceitos de território empregados na Geografia.
\end{abstract}

Palavras-chave: Logística. Fluxos. Território. Campos Gerais do Paraná.

\begin{abstract}
Between the late 1980s and during the 1990s the Brazilian economy has experienced a strong opening to international trade, which caused the (re)emergence of the issue of regional development based on the search for optimization and delivery in order to intensify the flow of products and information, the specialization of production, and the enhancing of the division of labor. Therefore, territorial logistics returns to the national and regional political agendas as a way to make companies more competitive, as in the case of projects such as the Industrial Logistic Customs Center (CLIA), in the city of Ponta Grossa, and the Cargo Airport in the city of Tibagi, located in the Campos Gerais region, state of Paraná. The present article aims at demonstrating the limits of these projects according to the concepts of territory employed in Geography.
\end{abstract}

Keywords: Logistics. Flow. Territory. Campos Gerais of Paraná. 


\section{INTRODUÇÃO}

A globalização da economia trouxe ao campo das políticas públicas os imperativos da expansão das redes de infraestrutura e redução dos custos de logística, em nome da competitividade empresarial e territorial. Com efeito, a competição inter-capitalista exige sempre novas estratégias de organização territorial que abarquem o crescimento do volume de circulação de mercadorias e informações, que se traduzem na procura da otimização dos fatores logísticos em função da equação tempo/ custos na qual se decompõe o lucro.

São as grandes corporações empresariais que através de ciência, técnica e informação, reorganizam o espaço geográfico, resultando num rearranjo territorial que valoriza os lugares por sua eficácia e lucratividade, selecionando determinados centros polarizadores. O espaço geográfico é, assim, articulado enquanto espaço produtivo, estruturado e reestruturado para inserir-se na rede de circulação de mercadorias e informações (SANTOS, 1996).

A reestruturação territorial baseada na técnica pressupõe a existência de um espaço otimizado e fluido, daí falar-se em novos sistemas técnicos e normativos que permitem uma ação precisa sobre os territórios, uma ação planejada pelos agentes dominantes. Segundo Santos (1996, p.190), "Essa união da técnica e da ciência vai dar-se sob a égide de mercado. E o mercado, graças exatamente à ciência e à técnica, torna-se um mercado global".

Embora usualmente a técnica seja compreendida apenas pelas inovações tecnológicas, representa um conceito bem mais amplo, ligando-se ao conceito de território enquanto fenômeno logístico ou vertebrador dos fluxos econômicos.

A organização logística aparece como prioridade política ainda durante a Segunda Guerra Mundial, então integrada ao campo militar por meio das empresas fornecedoras de armamentos e mantimentos para o campo de batalha. Com o fim dos conflitos, a logística passa a ser alvo da atenção do meio corporativo civil, tornando-se elemento constitutivo de todas as grandes empresas transnacionais a partir da década de 70, quando se efetiva o modelo de acumulação flexível em escala mundial (HARVEY, 2003).

Implanta-se, assim, a logística como componente articulador das ações competitivas territoriais. No Brasil, esse novo modelo de gerenciamento do território se faz sentir com mais força no início dos anos 90, diante das necessidades produzidas a partir da abertura comercial e inserção ampliada da produção nacional nos mercados internacionais. Mas seus elementos básicos podem ser sentidos desde a chegada dos grandes grupos agroindustriais ao Centro-Sul, ainda na década de 70, através do "complexo da soja", e que marcam a geografia dessa região até os dias de hoje. Gerida por grandes empresas com apoio científico, tecnológico e informacional, torna-se a logística preocupação crescente de políticas orçamentárias também dos vários níveis político-administrativos do Estado brasileiro (União, Estados e Municípios).

$\mathrm{Na}$ pesquisa procurou-se destacar o planejamento logístico do território brasileiro e algumas políticas públicas, enfatizando a integração do local-regional aos mercados globais e buscando a homogeneização do território nacional. Os modais de transportes, a partir do desenvolvimento logístico, tornam-se componentes acionadores no planejar da logística regional e primordiais para os usos econômicos planejados para os territórios. As possibilidades de utilização de mais de um modal de transporte multimodalidade e intermodalidade são vistas como acionadores de grandes vantagens econômicas na produção, com a sua regulamentação a nível nacional. 
A análise dos fluxos da região dos Campos Gerais foi elaborada para detectar a viabilidade de implementação do CLIA e do Aeroporto Internacional de Cargas de Tibagi. Tais projetos se constituem em plataformas logísticas para o aparelhamento regional, mediante os imperativos de circulação dos fluxos na região. Sendo analisados quais destes equipamentos estariam mais condizentes às necessidades do lugar, a partir dos tipos de fluxos oriundos da produção regional, destinados a circulação para mercados internos e externos.

É intento a análise dos projetos de implementação destes equipamentos, considerando o mais viável, ou seja, o que possui mais suporte de competitividade, a partir do valor agregado dos fluxos produzidos na região e quanto à circulação, tornando-os assim, mais competitivos nos mercados.

Desta forma, destacamos que dois importantes projetos de implantação de objetos com fins logísticos prometem nova reestruturação territorial nos Campos Gerais do Paraná, quais sejam, o CLIA de Ponta Grossa e o Aeroporto Internacional de Cargas de Tibagi. Os discursos de seus proponentes e defensores prometem o atendimento do bem geral da comunidade, embora experiências análogas estudadas na Geografia demonstrem a apropriação desses objetos logísticos por reduzido número de grandes corporações empresariais. Assim, resta-nos determinar a necessidade econômica, territorial ou social desses projetos logísticos para a região estudada, confrontando os múltiplos usos do território.

O desenvolvimento da análise sobre os novos objetos logísticos projetados para a região dos Campos Gerais pauta-se na aplicação do conceito de logística centrado no viés das redes de transportes e configuração dos sistemas de mobilidades territoriais, como elemento vertebrador do espaço geográfico da globalização.
Assim, procede-se um resgate do conceito de território na Geografia, baseado na definição de espaço geográfico, simultaneamente, enquanto campo de poder e meio técnico-científico-informacional, usado pelas grandes corporações. Esse conceito geográfico mais amplo traz a questão logística para a discussão das necessidades de novos objetos territoriais pelos atores hegemônicos, que não devem ser confundidos com os atores proponentes dos projetos em questão.

\section{O DESENVOLVIMENTO LOGÍSTICO}

Para os desenvolvimentistas da escala nacional à local, especialmente quando da globalização econômica aprofundada a partir dos anos 1970-80, o desenvolvimento territorial depende da disposição da sociedade em mirar objetivos comuns e de absorver uma variedade de experiências internacionais ${ }^{1}$. Com efeito, a solidariedade das escalas - global, regional e local - é a marca de nosso tempo, ditada pela universalização e integração dos sistemas técnicos (SANTOS, 1996).

A meta do desenvolvimento territorial cada vez mais é determinada pelas vantagens concorrenciais obtidas do aparelhamento do território e das inovações das técnicas e tecnologias, que redefine os contornos da produção, das relações de trabalho e da dinâmica dos territórios.

A intensificação da competição entre corporações produtivas e financeiras internacionais na disputa pelo controle de espaços globais ocorre pela formação de redes envolvendo pontos (lugares) descontínuos do planeta, através do

${ }^{1}$ Para Galvão (2003, p. 7), “O aprendizado coletivo das inovações é chave para o desenvolvimento regional, com repercussões nos rumos da economia nacional e em escala menor, quanto às perspectivas dos vários subespaços da economia". 
emprego de tecnologias e informação, de forma a tornar os territórios (e o tempo) mais ágeis, competitivos e dinâmicos:

É fato que o crescimento econômico e, por conseqüência, o desenvolvimento de uma região requer disponibilidade de infra-estrutura para suportar as atividades econômicas. Por outro lado, o processo de desenvolvimento regional gera a necessidade de investimento em infra-estrutura para a continuidade do processo. (VARGAS, 2007, p. 85).

O efeito intrínseco do processo de disputa por mercado entre grandes corporações é o acirramento da competitividade dos territórios, medido por sua organização produtiva interna, muitas vezes gerando a fragmentação das solidariedades produtivas regionais e nacionais ${ }^{2}$. É nesse sentido que Rückert (2004, p. 3) comenta que "a literatura sobre política pública, que tem documentado a decrescente influência do Estado-Nação, tem trazido a questão da iniciativa local no desenvolvimento econômico", tornado o local (município) um dos atores importantes do desenvolvimento territorial. Com efeito, a busca de competitividade empresarial e territorial faz a escala local ganhar força singular, acirrando novamente a concorrência territorial; e daí a ênfase atual das políticas territoriais dirigidas ou com envolvimento direto dos atores locais para o alargamento do aparelhamento produtivo.

No Brasil, as experiências de políticas de desenvolvimento territorial em escala local-regional adquirem mais relevância nos anos 80, sob o argumento das reformas liberais e da procura do desenvolvimento independente para os espaços locais. Segundo Galvão (2003, p. 6):

2- Para Galvão, “Na globalização, a competitividade emergiu como parâmetro imprescindível para a sobrevivência e afirmação das empresas e países nos mercados mundiais. Diante disso, assistiu-se a um esforço de redesenho de regras comerciais, que facilitasse a interpretação e o livre trânsito das estruturas globais". (GALVÃO, 2003, p. 60-61).
No novo contexto mundial, como surgem algumas experiências concretas, a possibilidade de associação entre políticas de desenvolvimento regional e estratégias de inovação vem se mostrando um campo promissor de intervenção.

Assim, no Brasil multiplicaram-se as experiências de desenvolvimento territorial que distinguem a força do processo globalizante e a valorização das diversidades econômicas, sociais e das políticas locais. Nos anos 90, as políticas federais também passam a incorporar essas novas estratégias de desenvolvimento territorial com ênfase no local. Essa convergência de atores ${ }^{3}$ dos diversos níveis político-administrativos é destacada por Rückert (2004, p. 3):

Interpretar o poder relacionado ao território significa relacioná-lo à capacidade dos atores de gerir, de implantar políticas econômicas e tecnológicas, com incidência estratégica no território, por parte tanto do Estado como dos múltiplos atores do/no poder, em alianças ou conflitos na gestão de políticas por capitais privados e por segmentos civis que representam as diferentes regiões do território.

Os ardilosos projetos de inovação e (re) estruturação logística promovidos pelos governos locais com grupos de interesse e corporações privadas, compõem o panorama da gestão do território. Nessa concepção, o Estado é chamado a organizar e articular as ações dos distintos atores, promovendo a fusão entre público e privado (AUED e ALBUQUERQUE, 2005) ${ }^{4}$.

\footnotetext{
${ }^{3}$ De acordo com Claude Raffestin (1993, p. 152): “(...) do Estado ao indivíduo passando por todas as organizações pequenas ou grandes, encontram-se atores sintagmáticos que produzem o território(...). O território se forma a partir do espaço, é o resultado de uma ação conduzida por um ator sintagmático (ator que realiza um programa) em qualquer nível".

${ }^{4}$ Com efeito, a Constituição da República Federativa do Brasil de 1988, em seu Artigo 21, inciso IX, infere que: “Compete à União elaborar e executar planos nacionais e regionais de ordenação do território e de desenvolvimento econômico e social".
} 


\section{LOGÍSTICA E SELETIVIDADE SÓCIO-TERRITORIAL}

A partir das estruturas tecnológicas e das articulações empresariais, o espaço geográfico adquire nova importância ao vincular-se às instâncias econômicas e culturais; mas o termo cultural aparece aqui num sentido bastante estreito, o de cultural produtivo ou organizacional.

O processo de desorganização - (re) organização sócio-temporal da globalização está ligado direta ou indiretamente à logística através das transformações e interligações dos espaços sócio-econômicos, criando a inserção e, principalmente, a exclusão de populações e territórios.

O setor empresarial (privado e público) acelera a formação de verdadeiras teias complexas de circulação, através de redes técnicas com utilização de tecnologias de ponta. Na implantação de infraestruturas diversas destacam-se os meios de transporte e de telecomunicações, cujo desenvolvimento "participou vigorosamente do jogo entre separação das atividades e unificação organizacional dos comandos". (SANTOS; SILVEIRA, 2005, p. 73).

As estratégias logísticas envolvem um grande controle e autonomia das tecnologias, efetivando-se sobre os territórios. Mas, o "lugar" que não oferecer atrativos, benefícios e/ou vantagens nas estratégias empresariais, não será selecionado, ou seja, não fará parte da rede. A dotação de logística de um determinado lugar pode desencadear também conflitos entre lugares, pois competirão entre si para oferecer mais atrativos para as empresas.

As corporações mais influentes (aquelas com maior poder de articulação política) são as que se efetivam no espaço ao organizar as infraestruturas e instalar os equipamentos necessários para seu funcionamento. Enquanto espaço de circulação, a logística transforma determinados territórios caracterizando-os como centros de comandos de mercadorias para toda uma região, ao mesmo tempo em que condena outros a profundas desvalorizações de seu papel na rede. Conforme Santos e Silveira (2006, p. 294): “Os primeiros seriam do ponto de vista da produtividade, da competitividade, "espaços luminosos", enquanto o resto do território chamar-se-ia "espaços opacos"."

O território é parte indissociável da estratégia competitiva empresarial ao possibilitar a organização de estruturas de produção, de armazenagem e de distribuição das empresas. Assim, aparece como dimensão essencial do capital produtivo - e também do capital financeiro (bancos, financeiras) -, possibilitando gerenciar e realizar a dominação do mercado.

Os fluxos de informações são decisivos para a circulação do produto, com a finalidade de efetivar níveis de serviços adequados, de eficiência e rapidez do capital, e sempre a um custo mínimo:

Nesse arcabouço levamos em conta tanto as técnicas que se tornaram território, com sua incorporação ao solo (rodovias, ferrovias, hidrelétricas, telecomunicações, emissoras de rádio e TV, etc.), como os objetos técnicos ligados à produção (veículos, implementos) e os insumos científicos (sementes, adubos, propagandas, consultoria) destinados a aumentar a eficácia, a divisão e a especialização nos lugares. (SANTOS; SILVEIRA, 2005, p. 22).

O transporte influencia diretamente nos custos logísticos ao representar até 2/3 destes dependendo dos modais utilizados e das condições técnicas e naturais de operação, bem como dos seus custos de gerenciamento (conservação) ${ }^{5}$. A escolha dos modais depende da acessibilidade, segurança, rapidez e, principalmente,

\footnotetext{
${ }^{5} \mathrm{Na}$ década de 1950, iniciam-se estudos mais específicos ligados a problemas logísticos nos meios industriais e comerciais. Para Ballou (2001, p. 19) “o problema a ser enfrentado pela logística é diminuir os gastos entre a produção e a demanda, de maneira que os consumidores tenham os bens e serviços quando e onde quiserem e na condição física que desejar".
} 
dos custos envolvidos. Dependendo da demanda da carga ou oferta dos serviços, o transporte poder ser unimodal (um único modo de transporte), intermodal (envolve dois ou mais modos de transportes, ainda que cada transportador emita um documento e responda individualmente pelo serviço que presta) e multimodal (vincula o percurso da carga a combinações dos meios, ainda que sob um único documento de transporte).

\section{A LOGISTÍCA DO TERRITÓRIO}

Os meios de movimentação representam elementos basilares para a aquisição e conservação do controle das empresas dominantes. De acordo com Silva Junior (2004, p. 122), a logística é entendida como:

[...] um dos elementos fundamentais responsáveis pela circulação de mercadorias e se define como sendo um conjunto de técnicas e tecnologias utilizadas com a finalidade de proporcionar fluidez a partir da aceleração da circulação geográfica, obtida com a realização de operações mais velozes e racional.

A logística oferece às grandes empresas capacidade de articulação de seus interesses pelo planeta, de forma a abarcar lugares cada vez mais afastados, estabelecendo uma única voz de comando: a sua própria. O domínio dos meios de movimentação e de comunicação das empresas se efetiva através dos sistemas de circulação modernos que desempenhem o papel presente e indispensável de fluidez:

Uma vez que a área de mercado tem tendência a ampliar-se e estender-se a todo o território da nação, ou, mesmo, para além dele, é indispensável transformar as massas produzidas em fluxos, para reaver o dinheiro investido e reiniciar o clico produzido. Quem o fizer mais rapidamente terá condições para tornar-se o mais forte. (SANTOS, 1992, p. 62-63).
Os manuais de administração ensinam que a logística tem como missão prover o melhor, maior e mais eficiente nível de rentabilidade nos serviços de distribuição aos clientes e consumidores através do planejamento, organização e controle efetivo das atividades de movimentação, que visem facilitar o fluxo de circulação, a rentabilidade, a influência e o poder de comando de empresas. Assim, a "logística agrega valor a produtos e serviços essenciais para a satisfação do consumidor e o aumento das vendas." (BALLOU, 2006, p. 26). Ainda no entender de Silva Junior (2004, p. 122):

Em escala temporal, entendemos que a logística é hoje, a organização técnica do capital baseado em infra-estruturas fixa de transportes (como rodovias, ferrovias e hidrovias), meios de transportes (como por exemplo, trens e caminhões) e nas tecnologias da informação e comunicações, tendo como objetivo proporcionar a otimização dos processos produtivos. Na base desses processos, está a redução dos custos sempre com aumento de fluidez.

De acordo com a Associação Brasileira de Logística (ASLOG, 2005/2006), a logística é definida como "o conjunto de atividades que apresenta por objetivo a colocação, ao mínimo valor, de uma quantidade de produto, em um lugar e no tempo onde uma demanda permanece".

Em escala global, os sistemas logísticos eficientes são aqueles que permitem ao território organizar ou reorganizar de forma eficaz a circulação, o gerenciamento, a fluidez, o desempenho e as estratégias que culminem em resultados que deixem as grandes corporações em posição de vantagem sobre a concorrência. A promessa é de que também esses territórios selecionados se tornarão áreas centrais, de comando, de polarização, efetivamente salientando-se nos cenários regional e nacional e, em alguns casos, até mundial: " $\mathrm{O}$ próprio padrão geográfico é definido pela 
circulação, já que esta mais numerosa, mais densa, mais extensa, detém o comando das mudanças de valor no espaço" (SANTOS, 1996, p. 214).

Alguns objetos geográficos são importantes para proporcionar maior fluidez ao território, tais como portos, aeroportos, rodovias, ferrovias, centros logísticos integrados, etc., por possibilitarem de forma otimizada e acelerada a movimentação dos fluxos: "Esses sistemas técnicos atuais são formados de objetos dotados de uma especialização extrema. Isso é sobretudo válido para os objetos que participam dos sistemas hegemônicos" (SANTOS, 1996, p. 176).

Esses sistemas de objetos permitem uma ação mais concisa e eficiente sobre o território, objetivando a redução de gastos, tempos, distâncias, enfim, a competitividade a partir dos serviços logísticos. É para efetivar a competitividade das grandes empresas que a logística, como configuração dos sistemas de mobilidade territorial, é estratégica.

Em sua dimensão geográfica ou espacial a logística destaca a mobilidade. Assim, as redes de transportes e de comunicações ampliam a influência empresarial na estruturação dos territórios e reorganização do espaço. Esse se torna também um espaço normatizado, pois exige a regulamentação do uso (e dos conflitos entre empresas e das empresas com a sociedade) do território-logístico. Como afirma Santos (2005), o espaço geográfico é um sistema de objetos e de ações e, portanto, a análise dos territórios-logísticos envolve um conjunto de materialidades técnicas, normas e formas de gestão do território.

Assim, a logística do território deve contemplar os seguintes objetos e ações: empresas especializadas e seus equipamentos, bases técnicas informacionais e bases normativas (públicas e privadas). Encontramos tais determinados objetos geográficos, representados pelos CLIAs, pelas rodovias, pelos portos, pelos aeroportos e também pelos centros logísticos. É através da interligação desses objetos que se forma um sistema geográfico dotado de fluidez, base da competitividade empresarial e promotor da reestruturação do território.

A retomada do crescimento econômico brasileiro nas duas últimas décadas, embora modesto, tem significado a ampliação da esfera dos serviços, onde emergem novas necessidades logísticas para dar conta da articulação desses fluxos promovidos principalmente pelo crescimento das exportações agrícolas e minerais.

Contudo, a implantação/modernização dos sistemas logísticos brasileiros encontra dificuldades, caso da escassez orçamentária do setor público e desinteresse do setor privado, e caso das resistências sociais e das burocracias públicas, que podem ser definidas como "rugosidades do espaço" (SANTOS, 1996, p. 112), que pesam, sobretudo, sobre os territórios periféricos e impedem a fluidez efetiva de grandes empresas. É dessa forma que as políticas públicas de modernização vão ser perseguidas pelas sociedades locais, especialmente na forma de políticas territoriais supostamente capazes de reverter o abandono relativo ou desgaste dos equipamentos logísticos existentes.

Em Raffestin, aprende-se a ler o espaço geográfico enquanto "campo de forças", onde as relações de poder edificam e controlam os territórios:

É essencial compreender bem que o espaço é anterior ao território. $O$ território se forma a partir do espaço, é o resultado de uma ação conduzida por um ator sintagmático (ator que realiza um programa) em qualquer nível. Ao se apropriar de um espaço, concreta ou absolutamente (...)o autor "territorializa" o espaço. (RAFFESTIN, 1993, p. 143)

Raffestin afirma que "Território é o espaço da prática. Por um lado é o produto 
da prática espacial: inclui a apropriação efetiva ou simbólica de um espaço, implica na noção de limite - componente de qualquer prática - é a face vivida do poder." (1993, p. 103). Nessa perspectiva, revelam-se relações sociais e territoriais marcadas pelo poder; em que a compreensão do território perpassa pelo poder exercido por pessoas ou grupos, sem o qual não se define o território. Em outras palavras, o poder apresenta uma dimensão relacional evidente ao estar intrínseco em todas as relações sociais.

Assim, quando voltamos nosso olhar para a região dos Campos Gerais do Paraná percebemos que as propagandas e promessas de desenvolvimento em torno dos novos projetos de implantação de objetos logísticos, podem representar mais interesses particulares de um punhado de grandes empresas que propriamente $o$ interesse geral da sociedade. O território é mais amplo que o espaço empresarial, representando o espaço da cidadania.

$\mathrm{Na}$ região dos Campos Gerais do Paraná, acena-se para a implementação de dois grandes projetos logísticos, aliados a um sistema logístico preexistente. Os grupos de interesse formados em torno desses projetos buscam sua inserção nas políticas públicas e aliados no setor privado. Em troca, prometem uma reestruturação do território capaz de promover desenvolvimento econômico e social para além dos interesses das grandes empresas instaladas na região.

O primeiro desses projetos refere-se à implementação do CLIA de Ponta Grossa, um centro logístico e aduaneiro de interior, a ser custeado por investimentos públicos e privados. O CLIA visa a armazenagem de mercadorias e ativação da integração na movimentação de cargas aos portos e aeroportos da região. A possibilidade de utilizar mais de um modal de transporte e o aproveitamento dos sistemas logísticos preexistentes projetam-se como vantagens do território para atender grandes empresas e também empresas locais e regionais na armazenagem, escoamento e desembaraços aduaneiros, diminuindo custos e dinamizando processos. Com efeito, o estrangulamento logístico até o Porto de Paranaguá se faz evidente, bem como os fluxos de mercadorias produzidas na região já parecem justificar a descentralização dos processos aduaneiros para determinados locais interiores. A questão aqui parece ser mais de vontade política na efetivação da descentralização dos trâmites burocráticos do comércio exterior que de custos financeiros.

Ainda que as grandes empresas agroindustriais venham a continuar a dominar os fluxos externos, não parece que o espaço dos pequenos produtores (e de pequenas empresas em outros ramos) venha a ser afetado pela nova dinâmica logística resultante do projeto de implantação do CLIA. Ao contrário, espera-se mesmo que o CLIA facilite também aos pequenos exportadores ao possibilitar os serviços burocráticos de aduana mais proximamente das áreas produtoras.

O segundo projeto é representado pelo Aeroporto Internacional de Cargas dos Campos Gerais, no município de Tibagi, um mega-projeto que através da Companhia Vale do Tibagi (CATV) almeja, com investimentos supostamente apenas da iniciativa privada, implantar um aeroporto com quatro pistas, área de armazenagem e hangares para grandes aeronaves. Um empreendimento que pretende utilizar-se das redes de transporte terrestre existentes na região (rodovias e ferrovias) e aprimorar com mais um modal, o aéreo, bem como a intenção de implementação de uma hidrovia no rio Tibagi. Porém, a viabilidade econômica desse projeto esbarra na peculiaridade das cargas geradas na região e em seu entorno, em sua ampla maioria formada por commodities agrícolas, cuja 
competitividade internacional exige fretes finais marítimos, de menor custo que o aéreo. Tanto é verdadeiro que esse projeto não cativou os representantes das grandes indústrias da região, permanecendo restrito ao seu grupo formulador e setores da municipalidade de Tibagi.

\section{CONSIDERAÇÕES FINAIS}

A economia capitalista globalizada é marcada pela fluidez do território, base dos fluxos de mercadorias e certos tipos de informações, em que a rapidez de resposta à concorrência acaba por ser fator decisivo na disputa por mercados e fatias do lucro. Dessa forma, as grandes corporações e Estados mais poderosos estão em vantagem na seleção, estruturação e reestruturação dos territórios para beneficio próprio.

Esse espaço produzido e usado, ou simplesmente território, é cada vez mais normatizado e fragmentado entre centros de comando e de obediência e entre espaços luminosos e opacos; assim dotado de maior rapidez ou lentidão conforme sua inserção na economia globalizada.

A infraestrutura logística dos territórios interessa primeiro ao lucro, e preferencialmente ao grande lucro, e somente então, se possível, também às pessoas e pequenas empresas do lugar. Deste modo, o atual conceito de logística está fortemente embasado na visão da administração da economia e dos transportes, e desta forma entra como conceito estruturante das políticas públicas de desenvolvimento territorial. O planejamento logístico realizado não é o dos lugares e das comunidades que neles vivem, mas das grandes corporações que, inclusive, capturam de forma crescente as políticas orçamentárias das diversas esferas do Estado, ou seja, apropriando-se de recursos dos contribuintes.
Visualiza-se que os grandes projetos logísticos propostos para a região dos Campos Gerais do Paraná anunciam a inserção regional em novo patamar da competição global, mas efetivamente podem ser questionados quanto à eficácia em alcançar tal meta. O desembaraço aduaneiro do CLIA poderá trazer mais agilidade aos exportadores, mas seria exagero afirmar que esta é condição suficiente para ampliar as exportações dos pequenos e médios produtores da região. O projeto do aeroporto, ainda mais exagerado, apresenta-se tecnicamente superdimensionado diante das características das cargas geradas na região e em seu entorno. Como o aeroporto de Tibagi disputará cargas com outros aeroportos do estado que operam nos mesmos moldes, resta a reestruturação produtiva regional. Aí o discurso da execução totalmente privada do projeto falha enormemente, pois a proposta de criação de cargas através do fomento da fruticultura seria bancada pelo Estado, segundo seus idealizadores. E, além disso, outro obstáculo é a estrutura fundiária (e creditícia) da região, ainda baseada na grande propriedade pecuarista ou de produção de grãos. Em síntese, "essas terras têm dono" (ALBUQUERQUE, 2008, p. 221), e esse fato não pode passar ao largo de qualquer projeto logístico para o futuro da região que se pretenda efetivamente viável econômica, política, social e tecnicamente.

\section{REFERÊNCIAS}

ALBUQUERQUE, E. S. de. Modernização e produção da miséria nos Campos Gerais do Paraná. Revista de História Regional, Ponta Grossa, v. 13, n. 2, 2008, p. 221-245.

Associação Brasileira de Logística (Aslog). Disponível em: http://www.aslog.org.br/novo. Acessado em: 10 jul. 2009. 
AUED, I. M.; ALBUQUERQUE, E. S. de. O método da desconstituição do capital e a Geografia. Terra Livre, São Paulo, n. 24, 2005, p. 43-60.

BALLOU, R. H. Gerenciamento da cadeia de suprimentos/logística empresarial. 5 ed., Porto Alegre: Bookman, 2006.

Gerenciamento da cadeia de suprimentos: planejamento organização e logística empresarial. 4 ed., São Paulo: Bookman, 2001.

GALVÃO, A.C.F. Política de Desenvolvimento Regional e Inovação: lições para o Brasil da Experiência Européia. Tese de Doutorado. Universidade Estadual de Campinas - Instituto de Economia. Campinas, ago. 2003.

HARVEY, D. A condição pós-moderna: uma perspectiva sobre as origens da mudança cultural. São Paulo: Loyola, 2003.

RAFFESTIN, C. Por uma geografia do poder. Tradução de Maria Cecília França. São Paulo: Ática, 1993.

RÜCKERT A. A. Políticas territoriais, ciência e tecnologia e a ação de atores locais e regionais. $\mathrm{O}$ Pólo de Modernização Tecnológica da Serra, Rio Grande do Sul, Brasil. Sociologias, Porto Alegre, ano 6, n. 11, jan/jun 2004.

SANTOS, M.; SILVEIRA, M. L. O Brasil: território e sociedade no início do século XXI. Rio de Janeiro/ São Paulo: Record, 2005.

. A Natureza do espaço: técnica e tempo. Razão e emoção. São Paulo: Hucitec, 1996.

. Espaço e Método. São Paulo: Nobel, 1992.

SILVA JUNIOR, R. F. Geografia de redes e da logística no transporte rodoviário de cargas: fluxos e mobilidade geográfica do capital. Dissertação de Mestrado. Universidade Estadual Paulista. Presidente Prudente, 2004, 270 f.

VARGAS, C. R.; SCATOLIN, F. D. Investimentos e o Papel do estado na Economia Paranaense - na segunda metade do século XX. Revista Paranaense de Desenvolvimento, Curitiba, n. 113, p. 83-102 jul/dez, 2007.

Recebido em: 23/02/11 Aceito em: 29/04/11 